\title{
Seasonal influenza vaccination in Kenya: an economic evaluation using dynamic transmission modelling
}

Jeanette Dawa ${ }^{1,2^{*}}$ D , Gideon O. Emukule ${ }^{3}$, Edwine Barasa ${ }^{4,5}$, Marc Alain Widdowson ${ }^{6,7}$, Omu Anzala ${ }^{1}$, Edwin van Leeuwen ${ }^{8}$, Marc Baguelin ${ }^{9,10}$, Sandra S. Chaves ${ }^{3,11}$ and Rosalind M. Eggo ${ }^{9}$

\begin{abstract}
Background: There is substantial burden of seasonal influenza in Kenya, which led the government to consider introducing a national influenza vaccination programme. Given the cost implications of a nationwide programme, local economic evaluation data are needed to inform policy on the design and benefits of influenza vaccination. We set out to estimate the cost-effectiveness of seasonal influenza vaccination in Kenya.

Methods: We fitted an age-stratified dynamic transmission model to active surveillance data from patients with influenza from 2010 to 2018. Using a societal perspective, we developed a decision tree cost-effectiveness model and estimated the incremental cost-effectiveness ratio (ICER) per disability-adjusted life year (DALY) averted for three vaccine target groups: children 6-23 months (strategy I), 2-5 years (strategy II) and 6-14 years (strategy III) with either the Southern Hemisphere influenza vaccine (Strategy A) or Northern Hemisphere vaccine (Strategy B) or both (Strategy C: twice yearly vaccination campaigns, or Strategy D: year-round vaccination campaigns). We assessed cost-effectiveness by calculating incremental net monetary benefits (INMB) using a willingness-to-pay (WTP) threshold of $1-51 \%$ of the annual gross domestic product per capita (\$17-\$872).

Results: The mean number of infections across all ages was 2-15 million per year. When vaccination was well timed to influenza activity, the annual mean ICER per DALY averted for vaccinating children 6-23 months ranged between $\$ 749$ and $\$ 1385$ for strategy IA, \$442 and \$1877 for strategy IB, \$678 and \$4106 for strategy IC and \$1147 and $\$ 7933$ for strategy ID. For children $2-5$ years, it ranged between $\$ 945$ and $\$ 1573$ for strategy IIA, $\$ 563$ and $\$ 1869$ for strategy IIB, $\$ 662$ and $\$ 4085$ for strategy IIC, and $\$ 1169$ and $\$ 7897$ for strategy IID. For children 6-14 years, it ranged between $\$ 923$ and $\$ 3116$ for strategy IIIA, \$1005 and $\$ 2223$ for strategy IIIB, \$883 and $\$ 4727$ for strategy IIIC and $\$ 1467$ and $\$ 6813$ for strategy IIID. Overall, no vaccination strategy was cost-effective at the minimum (\$17) and median (\$445) WTP thresholds. Vaccinating children 6-23 months once a year had the highest mean INMB value at \$872 (WTP threshold upper limit); however, this strategy had very low probability of the highest net benefit.

(Continued on next page)
\end{abstract}

\footnotetext{
* Correspondence: jdawa@cartafrica.org

'KAVI-Institute of Clinical Research, College of Health Sciences, University of Nairobi, Nairobi, Kenya

${ }^{2}$ Washington State University Global Health Programs Kenya Office, Nairobi, Kenya

Full list of author information is available at the end of the article
}

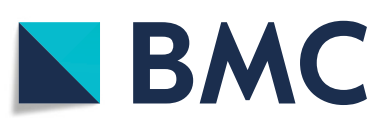

(c) The Author(s). 2020 Open Access This article is licensed under a Creative Commons Attribution 4.0 International License, which permits use, sharing, adaptation, distribution and reproduction in any medium or format, as long as you give appropriate credit to the original author(s) and the source, provide a link to the Creative Commons licence, and indicate if changes were made. The images or other third party material in this article are included in the article's Creative Commons licence, unless indicated otherwise in a credit line to the material. If material is not included in the article's Creative Commons licence and your intended use is not permitted by statutory regulation or exceeds the permitted use, you will need to obtain permission directly from the copyright holder. To view a copy of this licence, visit http://creativecommons.org/licenses/by/4.0/. The Creative Commons Public Domain Dedication waiver (http://creativecommons.org/publicdomain/zero/1.0/) applies to the data made available in this article, unless otherwise stated in a credit line to the data. 
(Continued from previous page)

Conclusion: Vaccinating children 6-23 months once a year was the most favourable vaccination option; however, the strategy is unlikely to be cost-effective given the current WTP thresholds.

Keywords: Dynamic transmission model, Economic evaluation, Cost-effectiveness, Influenza vaccine, Low- and middle-income countries, Vaccine timing, Vaccine target group

\section{Background}

Influenza is an important cause of respiratory illness in Kenya, especially in children under 5 and, in particular, young children under $2[1,2]$. In 2016, the Kenya National Immunisation Technical Advisory Group (KENI TAG) recommended annual seasonal influenza vaccination for children 6-23 months of age [3]. KENITAG further recommended pilot projects to generate additional local data to inform implementation of a nationwide influenza vaccination policy. In particular, KENI TAG requested that local evidence be generated on influenza vaccine cost-effectiveness, because their recommendation largely relied on studies in non-African countries [4-6]. Given the cost implications of a nationwide programme, local economic evaluation data are needed to inform policy on the design and benefits of influenza vaccination in Kenya.

In countries with year-round influenza activity, the World Health Organization (WHO) recommends vaccination with the most recent influenza vaccine formulation before the primary peak in influenza activity $[7,8]$. In Kenya, cases are observed year round [9], with an equal number of cases occurring during the Northern Hemisphere $(\mathrm{NH})$ and Southern Hemisphere $(\mathrm{SH})$ seasons [10]. There are no published influenza vaccine cost-effectiveness studies in Kenya. In other tropical settings with year-round influenza transmission, there is some quantification of the effect of elderly vaccination [11], but no evidence of the impact of vaccinating children.

Although evidence from intervention and observational studies on the indirect effects of influenza vaccination is limited [12], dynamic transmission models have proven useful to evaluate the effect of public health interventions targeted at infectious diseases, because they incorporate direct and indirect effects of vaccination [13, 14]. By doing so, it is possible to identify the optimal target group and coverage level for vaccination programmes, especially where the impact of herd immunity significantly alters disease incidence and outcomes [15].

Using a dynamic transmission model, researchers in the United Kingdom (UK) showed that expanding the influenza vaccination programme to include children 516 years of age would be the most efficient strategy in further reducing morbidity and mortality associated with influenza in their country [16]. We adapted this age- stratified transmission model to estimate the burden of disease associated with seasonal influenza from 2010 to 2018 in Kenya. Our objectives were to identify the most cost-effective target group and to estimate the ideal timing and vaccine formulation by comparing the incremental cost-effectiveness ratios (ICER) per disability-adjusted life year (DALY) averted for different vaccination scenarios. This information may assist policy makers in determining optimal seasonal influenza vaccination strategies.

\section{Methods}

We obtained influenza surveillance data among patients hospitalised with severe acute respiratory illness (SARI) in Kenya from 2010 to 2018 and defined peaks in influenza activity. We fitted a transmission dynamic model to these epidemics by fitting the number of SARI cases, the number of tested samples and the number of influenza virus-positive samples, by week and age group $(<1,1-5$, $6-14,15-19,20-49$ and $\geq 50$ years of age). The viruspositive samples were categorised by influenza type and subtype: influenza B, influenza A H1N1pdm09 (A(H1N1)pdm09) and influenza A H3N2 (A(H3N2)). We set each influenza year from September to August the following year, except at the start of the study period because data were available from January 2010. Using epidemiological information, we then estimated the number of asymptomatic cases, symptomatic cases, deaths and DALYS due to influenza each year. Using health care utilisation data and costs of illness, we determined the number of health care utilisation events and costs of influenza each year. Thereafter, we modelled different influenza vaccination strategies and determined the ICER per DALY averted and incremental net monetary benefit (INMB) of each vaccination strategy.

\section{Influenza surveillance data}

We used weekly numbers of patients hospitalised with SARI identified through the Kenyan national SARI surveillance system from 1 January 2010 to 31 December 2018 (Additional file 1). This system is run by the Ministry of Health in a few health facilities and supported by the Centers for Disease Control and Prevention (CDC), Kenya [9]. There are approximately 759 hospitals with inpatient capacity in the country, of which 50 have a bed capacity of $\geq 200$ [17]. We used data from 5 of these 
larger health facilities: Siaya, Nyeri, Mombasa, Nakuru and Kakamega County Referral Hospitals where a wellestablished surveillance system was in place, and comprehensive data for the full study period was available (Additional file 2, section 1). We excluded data from circulation of influenza $\mathrm{A}(\mathrm{H} 1 \mathrm{~N} 1) \mathrm{pdm} 09$ during the pandemic period (January 2010 to December 2011) to focus on seasonal epidemics, because the influenza A(H1N1)pdm09 pandemic did not present normal influenza activity in Kenya and was associated with higher level of severity than other circulating strains [18].

Hospitalised patients with SARI were included in the surveillance system if illness onset was acute (within 14 days from admission date) and they presented with fever (or history of fever) and cough. Nasopharyngeal (NP) and oropharyngeal (OP) samples were tested by realtime reverse transcription-polymerase chain reaction (rRT-PCR) from a random subset of these hospitalised patients [9]. Of the 24,480 cases identified through the SARI surveillance system, $80 \%$ were tested for influenza virus.

We defined hospital-specific catchment populations around each SARI surveillance site as the population within 10 kilometres $(\mathrm{km})$ of the hospital. This was informed by a study in Kenya that showed $90 \%$ of children admitted with symptoms of a febrile illness, reside within $10 \mathrm{~km}$ of the health facility (Additional file 2, section 1) [19].

\section{Defining epidemics}

Kenya has year-round influenza transmission. To allow fitting and simulation of vaccine impact in the model, we used the following activity-period decision rule. We identified periods of high influenza activity as $\geq 2$ successive weeks where the proportion of subtype-specific testpositive cases was greater than the average weekly proportion during the entire study [20]. A period ended when there were $\geq 2$ consecutive weeks where the proportion of subtype-specific positive cases was less than the weekly average. In addition, influenza-positive cases had to be observed in at least 3 of the 5 surveillance sites during the identified period so that periods identified were of widespread transmission. During model fitting, start and end dates were adjusted to centre the model peak to observed cases. If the posterior mean estimate of the net reproduction number at the start of the simulation was less than 1 (i.e. little evidence of sustained transmission), the period was excluded.

\section{Transmission model}

We modified an age-stratified Susceptible-ExposedInfectious-Recovered (SEIR) compartmental modelling framework previously used to inform influenza vaccination policy decision-making in the UK (Additional file
2 , section 2) $[16,21]$. The main differences between the UK model and Kenya model and their impact on the findings are summarised in the supplementary text (Additional file 2, section 7).

Mixing between age groups was governed by social contact survey data from Kenya collected from the coastal region [22]. The latent period was fixed at 0.8 days, and the infectious period at 1.8 days [16]. Probability of transmission and the fraction of the population susceptible varied each season, and the values were estimated during fitting. The SEIR compartments were stratified into vaccine-naïve and vaccinated populations. The model is available in the fluEvidenceSynthesis package in $\mathrm{R}[23,24]$.

\section{Parameter inference}

Parameters of the model were fitted to Kenyan surveillance data using Bayesian evidence synthesis [16]. For each season, we inferred the transmissibility of the virus, the susceptibility of 3 age groups ( $\leq 14$ years, $15-49$ years, $\geq 50$ years), the initial number of infections, the number of infections introduced from outside Kenya, the probability of identifying an influenza-positive patient within the catchment population in each of 3 age groups $(<1$ years, $1-5$ years, $\geq 6$ years) and the number of subtypespecific influenza cases in the whole Kenyan population during each epidemic. We determined the age groupings for susceptibility and ascertainment based on comparisons of the best fit of the model to the observed data.

Where there was more than one circulating subtype during a season, we fitted the model separately to each subtype. We ran 500,000 Markov chain Monte Carlo (MCMC) iterations after a burn in of 200,000. We thinned the chain to $2 \%$ and all results are presented from 10,000 samples from the joint posterior distribution. Posterior mean values and 95\% Bayesian credible intervals $(\mathrm{CI})$ are given.

\section{Vaccination component}

We considered 12 vaccination strategies using: (i) 3 age groups: $6-23$ months, $2-5$ years, $6-14$ years; (ii) 4 vaccination timings: vaccination campaigns in April-June, October-December, or both (to coincide with $\mathrm{NH}$ or $\mathrm{SH}$ vaccine availability), and year-round vaccination (Table 1). Vaccination coverage levels varied by strategy. We assumed that year-round vaccination would achieve higher coverage levels than shorter campaigns due to longer availability of vaccine and that vaccination coverage of older children would be slightly higher than younger children, based on findings from a demonstration vaccination programme in Kenya [25]. For biannual vaccination, we assumed that individuals would only be vaccinated once per year and that in each vaccination period only individuals who had not been vaccinated in 
Table 1 Vaccination scenarios modelled in three age groups and four vaccination timings

\begin{tabular}{|c|c|c|c|c|c|}
\hline & & \multicolumn{4}{|c|}{ Vaccination timing and uptake } \\
\hline & & $\begin{array}{l}\text { A: } \\
\text { Apr-Jun } \\
\text { SH vaccine }\end{array}$ & $\begin{array}{l}\text { B: } \\
\text { Oct-Dec } \\
\mathrm{NH} \text { vaccine }\end{array}$ & $\begin{array}{l}\text { C: } \\
\text { Apr-Jun and Oct-Dec } \\
\text { Both vaccines }\end{array}$ & $\begin{array}{l}\text { D: } \\
\text { Year-round } \\
\text { Both vaccines } \\
\end{array}$ \\
\hline \multirow[t]{3}{*}{ Age group } & I: $6-23$ months & $30 \%$ & $30 \%$ & $45 \%$ & $60 \%$ \\
\hline & II: $2-5$ years & $35 \%$ & $35 \%$ & $50 \%$ & $65 \%$ \\
\hline & III: 6-14 years & $40 \%$ & $40 \%$ & $55 \%$ & $70 \%$ \\
\hline
\end{tabular}

Coverage values were set based on influenza vaccination studies in Kenya [25] and local consultation.

NH Northern Hemisphere, SH Southern Hemisphere

the preceding 12 months would receive vaccine. Vaccination was assumed to occur at a constant rate during the vaccination period.

We assumed that the $\mathrm{NH}$ and $\mathrm{SH}$ vaccines provided "all-or-nothing protection", i.e. for $80 \%$ vaccine effectiveness (VE), $80 \%$ of vaccinated people receive $100 \%$ protection from infection [26]. Protection lasted from the time of vaccination up to the end of the subtype specific influenza activity period. Vaccine protection was restricted to an epidemic and was not carried forward to future epidemics. We assumed that the $\mathrm{NH}$ vaccine provided protection against influenza activity that began between September of the same year and February of the next year and did not protect against influenza activity beginning between March and August. Similarly, the SH vaccine provided protection against influenza activity that began between March to August of the same year and did not provide protection against activity starting either earlier or later than these months.

Influenza vaccine effectiveness varies each year and differs across age groups. To simplify the model, we used subtype-specific published values of overall influenza VE to set a fixed value of VE in the model as either good (70\%) or poor (42\%) in all target age groups. If published VE was $\geq 50 \%$, VE was modelled at $70 \%$ across all age groups; however, if VE was $<50 \%$, VE was set at $42 \%$ in the model (Additional file 2, section 3). The choice of a fixed influenza VE value was informed by a systematic review and was validated in the original UK study [16].

\section{Economic evaluation}

We used an economic evaluation decision tree to categorise infected individuals as asymptomatic, symptomatic with mild illness (upper respiratory tract (URT) infections) or symptomatic with severe illness (lower respiratory tract (LRT) infections) based on influenza challenge studies [27]. Those with mild illness were either seen at an outpatient clinic or were not medically attended, while patients with severe illness were either hospitalised or not. All those with mild illness were assumed to recover, while those with severe illness either recovered or died (Additional file 2, section 4).
We calculated DALYs from disability weights of mild upper respiratory infection, moderate lower respiratory tract infection, severe lower respiratory tract infection and death [28] (Additional file 2, section 4). We estimated the proportion of cases that attended outpatient clinics or were hospitalised using representative South African influenza-specific healthcare utilisation data [29] (Table 2). To estimate costs from a societal perspective, we used an influenza costing study that described direct medical costs, healthcare-related costs, and indirect costs of influenza illness among patients with influenza attending health facilities in Kenya [30] (Fig. 1) (Table 3).

Vaccine administrative costs were obtained from a vaccine delivery costing study in Kenya and Tanzania (Table 3) [31]. We set vaccine purchase price at \$3 US dollars (USD) per dose for a multi-dose vial, which was considered a reasonable price based on available market prices for the trivalent inactivated vaccine, if obtained through a negotiated agreement for low- and middleincome countries (LMICs). We tested the sensitivity of our results to this cost. Vaccine wastage was assumed to be 15\% [32]. Costs from before 2018 were adjusted to 2018 USD values using the annual Kenya gross domestic product (GDP) deflator values.

We calculated annual ICERs per DALY averted for all 12 strategies compared to no vaccination (base scenario), as influenza vaccination was negligible in Kenya during the study period. We time discounted DALYs by $3 \%$ [33]. Average annual ICERs per DALY averted were calculated for each vaccine strategy. A cost saving output resulted in an increase in benefit and overall decrease in total costs incurred. For each strategy, we calculated the probability that it had the highest INMB at willingnessto-pay (WTP) thresholds of $1-51 \%$ of the 2018 Kenya GDP per capita (i.e. between $\$ 17$ and $\$ 872$ per DALY averted), and used the results to construct costeffectiveness acceptability curves [34]. We then constructed cost-effectiveness acceptability frontiers depicting the highest probability for the most optimal strategy (i.e. the strategy with highest average INMB) [35].

In sensitivity analysis, we calculated DALYs with and without social weighting and time discounting [33]. Social weighting placed greater value on life lost from 9 to 
Table 2 Values for disease states and heath utilisation rates used in economic model. Mean and 95\% confidence interval (Cl) or proportions are given

\begin{tabular}{|c|c|c|c|c|}
\hline Item & Measure & Value & Distribution & Reference \\
\hline \multicolumn{5}{|l|}{ Disease states } \\
\hline $\begin{array}{l}\text { Proportion of influenza cases that develop any } \\
\text { clinical symptoms }\end{array}$ & Mean $(95 \% \mathrm{Cl})$ & $0.669(0.583-0.745)$ & Normal & [27] \\
\hline $\begin{array}{l}\text { Proportion of influenza cases that develop } \\
\text { upper respiratory tract symptoms/mild illness }\end{array}$ & Mean $(95 \% \mathrm{Cl})$ & $0.588(0.455-0.708)$ & Normal & [27] \\
\hline $\begin{array}{l}\text { Proportion of influenza cases that develop lower } \\
\text { respiratory tract symptoms/severe illness }\end{array}$ & Mean $(95 \% \mathrm{Cl})$ & $0.210(0.140-0.303)$ & Normal & [27] \\
\hline \multicolumn{5}{|l|}{$\begin{array}{l}\text { Proportion of influenza cases with severe illness } \\
\text { that die while hospitalised }\end{array}$} \\
\hline$<1$ year & Mean $(95 \% \mathrm{Cl})$ & $0.0274(0-0.0616)$ & \multirow[t]{7}{*}{ Truncated normal } & \multirow{7}{*}{$\begin{array}{l}\text { Influenza SARI surveillance } \\
\text { dataset (2010-2018) }\end{array}$} \\
\hline $1-5$ years & Mean $(95 \% \mathrm{Cl})$ & $0.0091(0-0.0322)$ & & \\
\hline $6-14$ years & Mean $(95 \% \mathrm{Cl})$ & $0.0108(0-0.0902)$ & & \\
\hline $15-20$ years & Mean $(95 \%$ Cl) & $0(0-0.1116)$ & & \\
\hline 20-49 years & Mean $(95 \% \mathrm{Cl})$ & $0.0331(0-0.0818)$ & & \\
\hline$\geq 50$ years & Mean $(95 \%$ Cl) & $0.1818(0.0909-0.3080)$ & & \\
\hline All ages & Mean $(95 \% \mathrm{Cl})$ & $0.0200(0.0035-0.0373)$ & & \\
\hline \multicolumn{5}{|l|}{$\begin{array}{l}\text { Proportion of deaths due to a respiratory illness } \\
\text { that occur in a health facility }\end{array}$} \\
\hline$<1$ year & Mean $(95 \% \mathrm{Cl})$ & $0.2794(0.2451-0.3140)$ & \multirow[t]{7}{*}{ Normal } & \multirow{7}{*}{$\begin{array}{l}\text { Siaya health demographic } \\
\text { and surveillance site dataset } \\
\text { (2010-2016) }\end{array}$} \\
\hline $1-5$ years & Mean (95\% Cl) & $0.2899(0.2471-0.3349)$ & & \\
\hline $6-14$ years & Mean $(95 \% \mathrm{Cl})$ & $0.4361(0.3534-0.5278)$ & & \\
\hline $15-20$ years & Mean $(95 \% \mathrm{Cl})$ & $0.5250(0.3750-0.6795)$ & & \\
\hline 20-49 years & Mean $(95 \% \mathrm{Cl})$ & $0.5067(0.4626-0.5525)$ & & \\
\hline$\geq 50$ years & Mean $(95 \% \mathrm{Cl})$ & $0.2715(0.2421-0.3012)$ & & \\
\hline All ages & Mean $(95 \% \mathrm{Cl})$ & $0.3287(0.3106-0.3474)$ & & \\
\hline
\end{tabular}

\section{Health care utilisation events}

Proportion of symptomatic influenza cases who attend outpatient clinic

$$
\begin{aligned}
& \text { 0-5 years } \\
& 6-12 \text { years } \\
& 13-17 \text { years } \\
& 18-24 \text { years } \\
& 25-44 \text { years } \\
& 45-64 \text { years } \\
& \geq 65 \text { years }
\end{aligned}
$$

Proportion of symptomatic influenza cases who are hospitalised

$$
\begin{aligned}
& \text { 0-5 years } \\
& 6-12 \text { years } \\
& 13-17 \text { years } \\
& 18-24 \text { years } \\
& 25-44 \text { years } \\
& 45-64 \text { years } \\
& \geq 65 \text { years }
\end{aligned}
$$

$\begin{array}{ll}\text { Mean }(95 \% \mathrm{Cl}) & 0.475(0.39-0.60) \\ \text { Mean }(95 \% \mathrm{Cl}) & 0.118(0.09-0.17) \\ \text { Mean }(95 \% \mathrm{Cl}) & 0.088(0.06-0.13) \\ \text { Mean }(95 \% \mathrm{Cl}) & 0.035(0.02-0.08) \\ \text { Mean }(95 \% \mathrm{Cl}) & 0.034(0.02-0.07) \\ \text { Mean }(95 \% \mathrm{Cl}) & 0.027(0.01-0.05) \\ \text { Mean }(95 \% \mathrm{Cl}) & 0.036(0.02-0.07)\end{array}$

0.718

Fixed value
[29] 
Table 2 Values for disease states and heath utilisation rates used in economic model. Mean and 95\% confidence interval (Cl) or proportions are given (Continued)

\begin{tabular}{|c|c|c|c|c|}
\hline Item & Measure & Value & Distribution & Reference \\
\hline $\begin{array}{l}\text { Proportion of hospitalised influenza cases who } \\
\text { sought care after discharge from hospital }\end{array}$ & Proportion & 0.105 & Fixed value & [30] \\
\hline $\begin{array}{l}\text { Proportion of non-medically attended influenza } \\
\text { cases where household members missed work } \\
\text { due to illness* }\end{array}$ & Proportion & Not known & - & - \\
\hline $\begin{array}{l}\text { Proportion of outpatient influenza cases where } \\
\text { household members missed work due to illness }\end{array}$ & Proportion & 0.518 & Fixed value & [30] \\
\hline $\begin{array}{l}\text { Proportion of hospitalised influenza cases where } \\
\text { household members missed work due to illness }\end{array}$ & Proportion & 0.848 & Fixed value & [30] \\
\hline $\begin{array}{l}\text { Proportion of non-medically attended influenza } \\
\text { cases where household members paid for } \\
\text { childcare during illness* }\end{array}$ & Proportion & Not known & - & - \\
\hline $\begin{array}{l}\text { Proportion of outpatient influenza cases where } \\
\text { household members paid for childcare during illness }\end{array}$ & Proportion & 0.18 & Fixed value & [30] \\
\hline $\begin{array}{l}\text { Proportion of hospitalised influenza cases where } \\
\text { household members paid for childcare during illness }\end{array}$ & Proportion & 0.29 & Fixed value & [30] \\
\hline
\end{tabular}

*These items were not included in the model as the values were unknown and difficult to estimate in the case of non-medically attended illness

56 years of age. We tested the impact of changing the vaccine purchase price to $\$ 1.5, \$ 3.0, \$ 6.0$ and $\$ 10.0$ per dose. Finally, we tested the impact of maintaining the same vaccine coverage across all age groups, i.e. 30\% coverage for once yearly campaigns, $45 \%$ coverage for twice yearly campaigns and $60 \%$ for year-round vaccination.

\section{Ethics statement}

Permission to undertake secondary data analysis of deidentified SARI surveillance data collected from patients admitted at county referral hospitals, was obtained from the Kenyatta National Hospital - University of Nairobi Ethics Review Committee (P18/01/2017).

\section{Results}

\section{Periods of high influenza activity}

We fitted 11 periods of high influenza activity in 7 of the 9 years of surveillance data. Five periods were associated with influenza $\mathrm{B}$, four with $\mathrm{A}(\mathrm{H} 3 \mathrm{~N} 2)$ and two with $\mathrm{A}(\mathrm{H} 1 \mathrm{~N} 1) \mathrm{pdm} 09$ (Fig. 2). In 1 year, there were 3 peaks in activity (September 2017-August 2018), and in 2 years, there were two peaks in

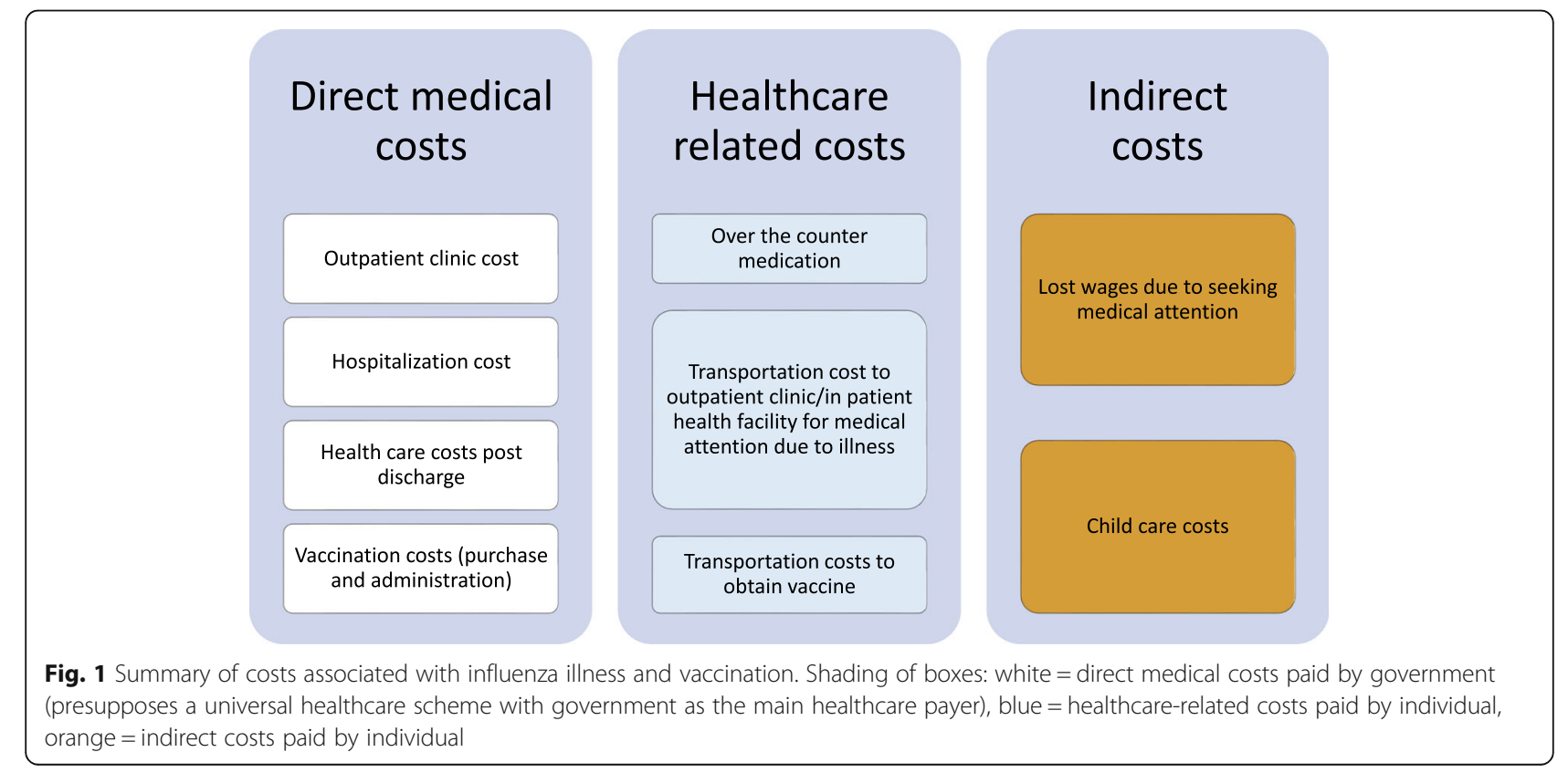


Table 3 Cost of influenza-associated illness in US dollars showing year of valuation

\begin{tabular}{|c|c|c|c|c|c|}
\hline Type of cost & Measure & Value in USD & Year & Distribution & Source \\
\hline \multicolumn{6}{|l|}{ Direct medical costs } \\
\hline $\begin{array}{l}\text { Facility based medical costs among influenza cases } \\
\text { attending outpatient clinic }\end{array}$ & Mean (SD) & $4.34(1.30)$ & 2014 & Normal & [30] \\
\hline Facility based medical costs among hospitalised influenza cases & Mean (SD) & $59.19(59.39)$ & 2014 & Normal & [30] \\
\hline $\begin{array}{l}\text { Health care costs after discharge among hospitalised influenza } \\
\text { cases who sought care after discharge }\end{array}$ & Mean (SD) & $3.28(6.19)$ & & Normal & [30] \\
\hline $\begin{array}{l}\text { Influenza vaccine purchase costs per dose } \\
\text { (varied in sensitivity analysis) }\end{array}$ & Fixed & 3 & 2018 & Fixed value & Assumption \\
\hline \multicolumn{6}{|l|}{ Vaccine administration cost per dose } \\
\hline $\begin{array}{l}\text { Supply chain cost per dose from national level to the } \\
\text { health facility }\end{array}$ & Mean & 0.43 & 2012 & Fixed value & [31] \\
\hline Provision of immunisation services at the health facility & Mean (SD) & $1.0(0.72)$ & 2012 & Normal & [31] \\
\hline \multicolumn{6}{|l|}{ Health care related costs } \\
\hline $\begin{array}{l}\text { Transportation costs among influenza cases attending } \\
\text { outpatient clinic }\end{array}$ & Mean (SD) & $0.40(0.87)$ & 2014 & Normal & [30] \\
\hline Transportation costs among hospitalised influenza cases & Mean (SD) & $5.03(8.32)$ & 2014 & Normal & [30] \\
\hline Transportation costs to receive vaccine at health facility & Man (SD) & $0.20(0.435)$ & 2014 & Normal & Assumption* \\
\hline $\begin{array}{l}\text { Health care costs prior to outpatient visit among influenza } \\
\text { cases who purchased medication before the outpatient visit }\end{array}$ & Mean (SD) & $1.39(3.90)$ & 2014 & Normal & [30] \\
\hline \multicolumn{6}{|l|}{ Indirect costs } \\
\hline $\begin{array}{l}\text { Lost wages among influenza cases not seeking formal health } \\
\text { care for mild illness }\end{array}$ & Fixed & 0 & - & Fixed value & Assumption \\
\hline $\begin{array}{l}\text { Lost wages among influenza cases attending outpatient visit } \\
\text { who report that household members missed work }\end{array}$ & Mean (SD) & $12.84(27.17)$ & 2014 & Normal & [30] \\
\hline $\begin{array}{l}\text { Lost wages among hospitalised influenza cases who report } \\
\text { that household members missed work }\end{array}$ & Mean (SD) & $42.02(41.54)$ & 2014 & Normal & [30] \\
\hline $\begin{array}{l}\text { Lost wages among those not hospitalised with severe } \\
\text { influenza illness }\end{array}$ & - & Not known & - & - & - \\
\hline $\begin{array}{l}\text { Childcare costs among influenza cases attending outpatient } \\
\text { clinic who report household members paid for childcare }\end{array}$ & Mean (SD) & $0.07(0.57)$ & 2014 & Normal & [30] \\
\hline $\begin{array}{l}\text { Childcare costs among hospitalised influenza cases who report } \\
\text { household members paid for childcare }\end{array}$ & Mean (SD) & $0.11(0.75)$ & 2014 & Normal & [30] \\
\hline Childcare among those not hospitalised for severe influenza illness & - & Not known & - & - & - \\
\hline
\end{tabular}

*For this cost no data existed and an assumption was made that the cost would be half of the transportation costs for outpatient care In the case where no data was available for costs incurred by non-medically attended cases, these costs were not included in the model SD standard deviation

activity (September 2010-August 2011, and September 2015-August 2016). September 2014-August 2015 and September 2016-August 2017 had no influenza activity periods that met the activity-period decision rule. The remaining 3 years had one period of influenza activity each (Table 4, Additional file 2 section 5).

Of the 11 periods of high influenza activity, 6 started between September and February and were suited to vaccination with the $\mathrm{NH}$ vaccine, and 5 started between March and August and were suited to the $\mathrm{SH}$ vaccine (Table 4). There were 8 instances where limited influenza activity did not meet the activity decision criteria (Additional file 2, section 5).

\section{Disease burden in the absence of vaccination}

We estimated that the mean number of infections per year (includes asymptomatic and symptomatic infections) was 2.0-15.0 million (Fig. 3, and Additional file 3, table 1), corresponding to a mean annual attack rate of $5-32 \%$. For years where more than one period of high influenza activity was modelled, the mean annual number of infections was 5.7-15.0 million and the mean annual attack rate was $12-32 \%$, while for years that had one peak, the yearly average was 2.0-6.7 million infections with a mean annual attack rate of $5-16 \%$.

We estimated that the average annual rate of infection was 4547-32,343 per 100,000 population. Rates of infection were highest among children $1-5$ years (Additional 


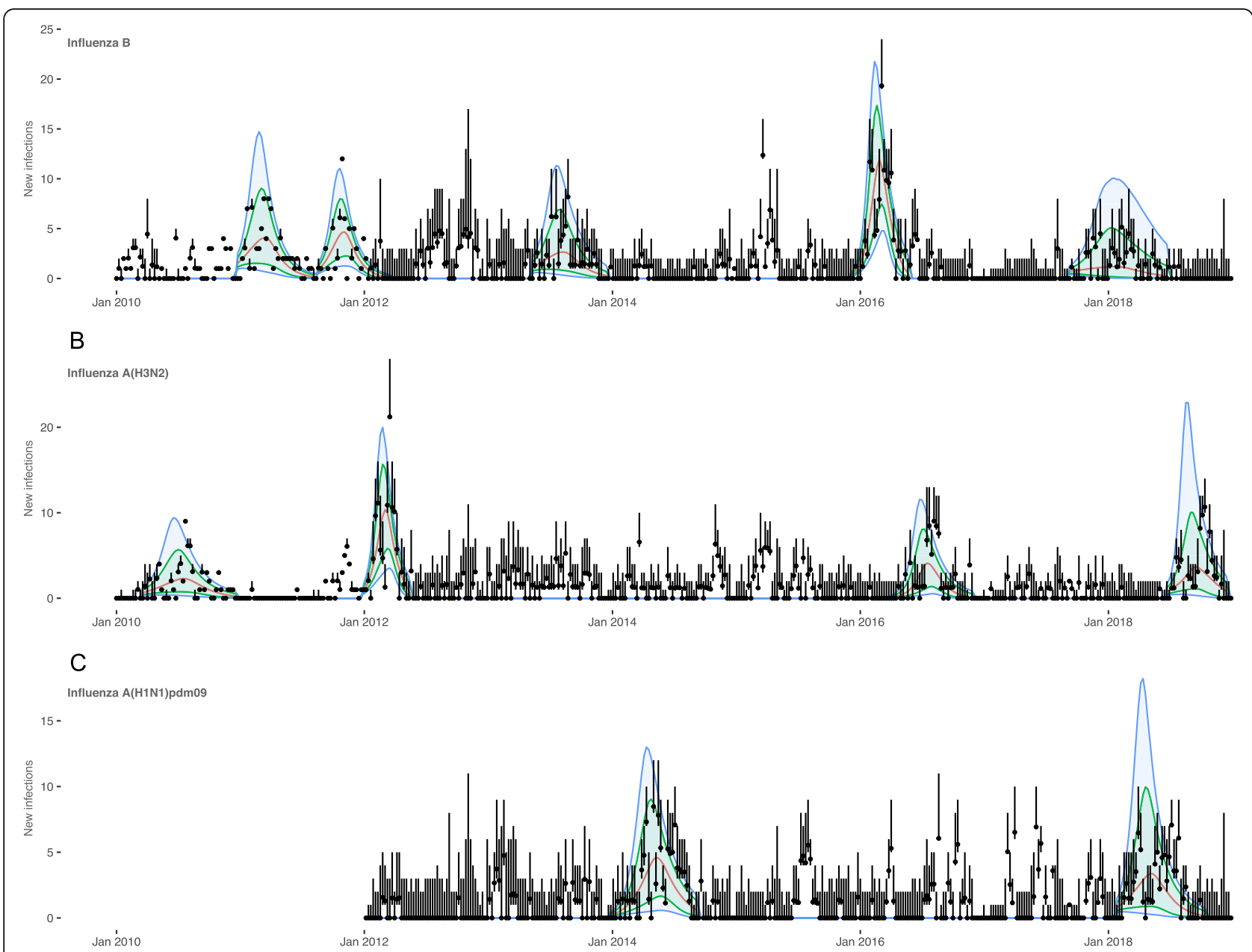

Fig. 2 Comparison of the fit of the model to weekly influenza-positive SARI cases in all ages. Positive cases detected in the influenza surveillance system (black) with hypergeometric 95\% confidence interval. Lines and shading represent the median (red) and 50\% (green) and $75 \%$ credible intervals (blue) of the fitted model. Note that the model is fitted to age-specific data, but age groups are aggregated here for clarity. a Influenza B. b Influenza A(H3N2). c Influenza A(H1N1)pdm09). Influenza A(H1N1)pdm09) data from January 2010 to December 2012 were excluded from the analysis

Table 4 Periods of high influenza activity, 2010-2018

\begin{tabular}{|c|c|c|c|c|c|c|}
\hline Year & $\mathrm{NH}$ season & Subtype & Vaccine match & SH season & Subtype & Vaccine match \\
\hline Jan 2010-Aug 2010 & & & & 03/2010-12/2010 & $\mathrm{A}(\mathrm{H} 3 \mathrm{~N} 2)$ & M \\
\hline 2010-2011 & 12/2010-08/2011 & B & M & 08/2011-03/2012 & B & M \\
\hline 2011-2012 & 12/2011-05/2012 & $\mathrm{A}(\mathrm{H} 3 \mathrm{~N} 2)$ & $U$ & & & \\
\hline 2012-2013 & & & & 05/2013-12/2013 & B & M \\
\hline 2013-2014 & 12/2013-09/2014 & A(H1N1)pdm09 & M & & & \\
\hline \multicolumn{7}{|l|}{ 2014-2015 } \\
\hline 2015-2016 & 11/2015-05/2016 & B & M & 03/2016-11/2016 & $\mathrm{A}(\mathrm{H} 3 \mathrm{~N} 2)$ & $U$ \\
\hline \multicolumn{7}{|l|}{ 2016-2017 } \\
\hline \multirow[t]{2}{*}{ 2017-2018 } & 09/2017-06/2018 & B & $U$ & 06/2018-12/2018 & $\mathrm{A}(\mathrm{H} 3 \mathrm{~N} 2)^{*}$ & $U$ \\
\hline & 01/2018-10/2018 & A(H1N1)pdm09 & M & & & \\
\hline
\end{tabular}

An influenza year begins in September and ends in August the following year. " $\mathrm{M}$ " means the vaccine was well matched to circulating strains (VE = 70\%) [16]. " $U$ " means vaccine was poorly matched to circulating strains $(\mathrm{VE}=42 \%)$ [16]. Blank cells indicate no detectable peak in influenza activity. ${ }^{*}$ There were no SH VE estimates available at the time, and we used VE values for the $\mathrm{NH}$ vaccine 


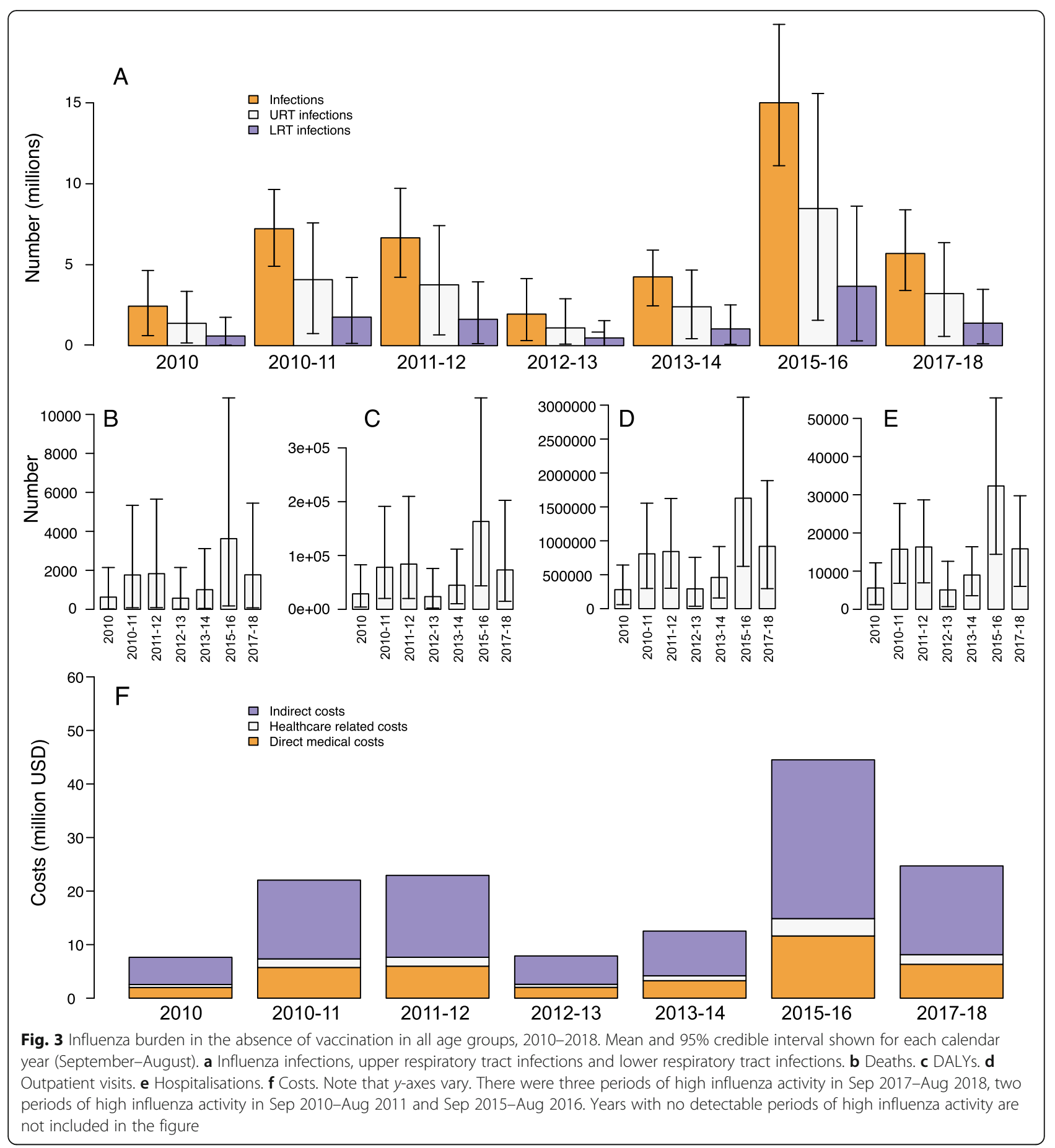

file 3 , table 2). There were 1.1-8.5 million upper respiratory tract infections, $0.5-3.7$ million lower respiratory tract infections and 570-3626 deaths annually (Fig. 3). Deaths were highest in the $1-5$ and $>50$ age groups. The average annual mortality rate was $1-8$ per 100,000 population. The highest mortality rates were observed in the $\geq 50,<1$ and $1-5$ age groups (Additional file 3 , table 2). There were 24,000-163,000 DALYs associated with influenza illness each year. Children $1-5$ years of age consistently contributed the highest number of DALYs (Additional file 3, table 1).

There were $0.3-1.6$ million outpatient visits and 5000-32,000 hospitalisations across all age groups each year (Fig. 3). The highest number of hospitalisations was observed among children 1-5 years of age (Additional file 3 , table 3 ). The annual mean rate of hospitalisation 
across all ages was $12-70$ per 100,000 population and was highest among children 1-5 years of age followed by those $<1$ year of age (Additional file 3 , table 2).

\section{Costs of influenza illness}

We estimated that the direct medical costs associated with outpatient and inpatient care were \$2.0-\$11.6 million per year (Fig. 3 and Additional file 3, table 4). Of this amount, outpatient costs accounted for approximately three quarters of total direct medical costs. Healthcare-related costs amounted to $\$ 0.6-\$ 3.2$ million annually while indirect costs associated with lost wages and childcare costs equalled $\$ 5.1-\$ 29.6$ million per year. The mean annual total cost of influenza-associated illness was \$20.3 million each year (annual average ranged between $\$ 7.6$ and $\$ 44.5$ million). Of note, indirect costs accounted for nearly $60 \%$ of all influenza-associated costs (Fig. 3 and Additional file 3, table 4).

\section{Comparison of vaccination strategies}

There were substantial differences in mean costs and outcomes by strategy (Fig. 4). Mean annual vaccination purchase and administrative costs were lower when vaccinating children 6-23 months (strategy I: \$4.3-\$10.5 million) compared to 2-5-year-olds (strategy II: \$9.9-\$22.7 million) and 6-14-year-olds (strategy III: \$25.3-\$54.4 million) (Additional file 3, table 5). Total societal costs associated with vaccination and illness were lowest with strategy I as compared to the other strategies: it cost an annual average of \$10.5-\$53.4 million for strategy I, $\$ 14.5-\$ 63.2$ million for strategy II and $\$ 28.7-\$ 87.8$ for strategy III (Table 5). Strategy III (vaccinating 6-14 year olds) required the highest

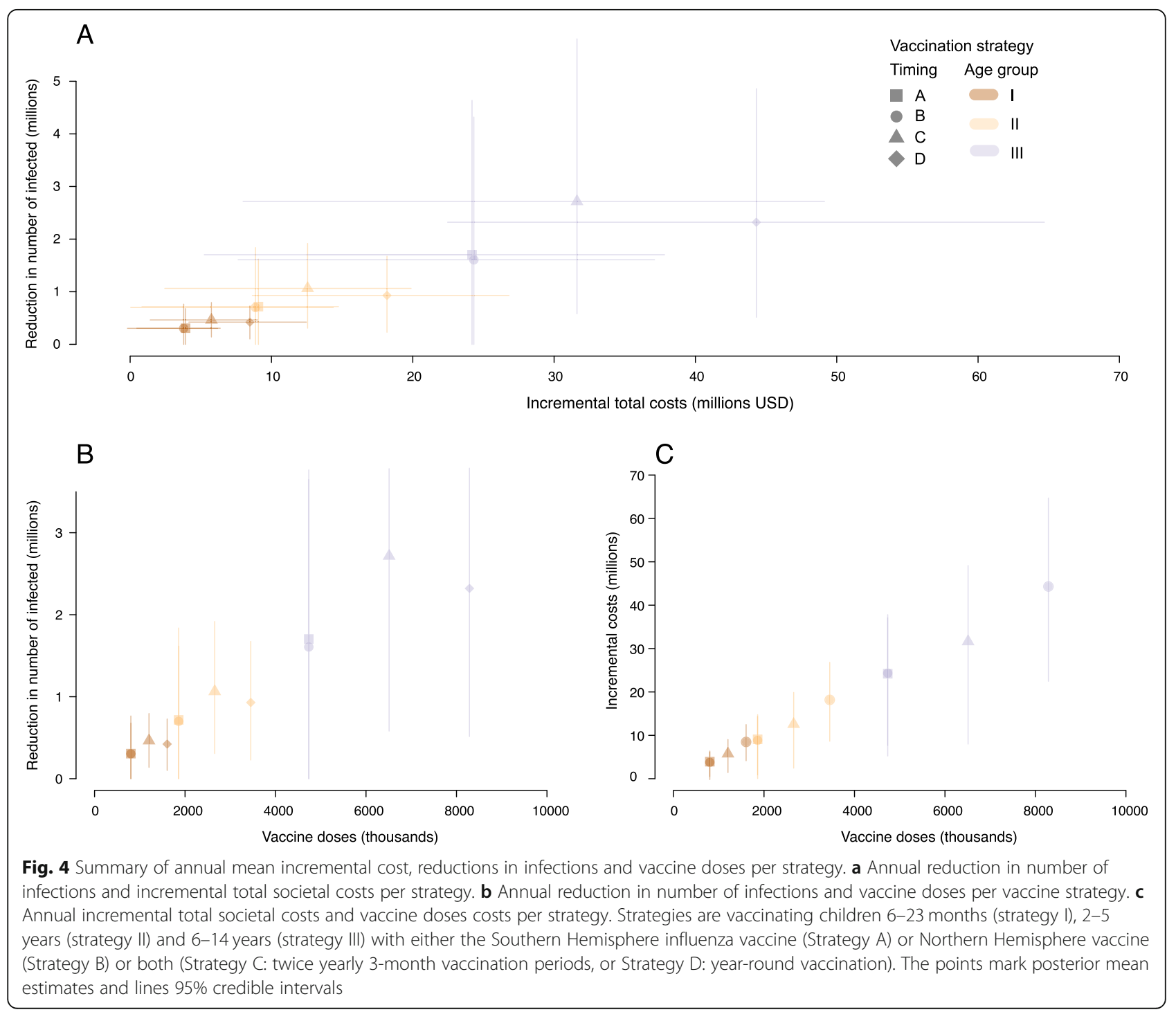




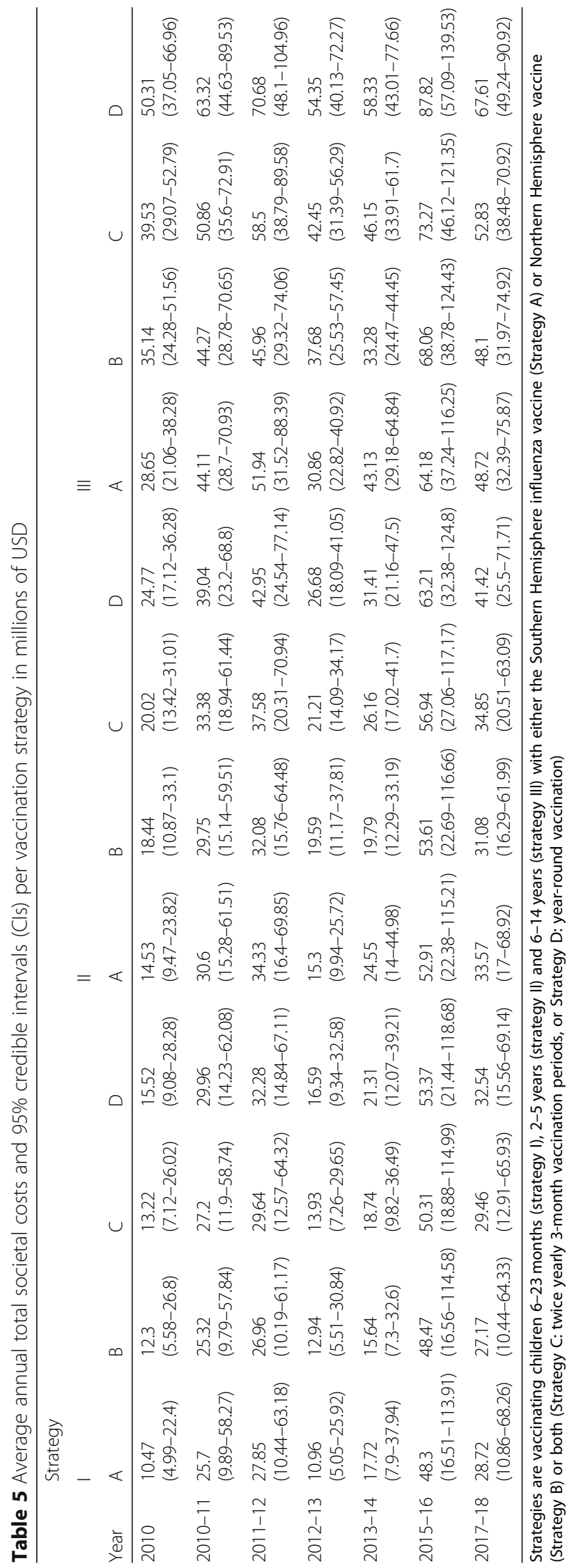


number of vaccine doses, resulted in the highest costs and led to the largest decrease in the number of infections (Fig. 4).

When vaccination was well timed/aligned to influenza activity, the annual mean ICER per DALY averted ranged between $\$ 749$ and $\$ 1385$ per DALY averted for strategy IA, $\$ 442$ and $\$ 1877$ for strategy IB, $\$ 678$ and $\$ 4106$ for strategy IC and $\$ 1147$ and $\$ 7933$ for strategy ID. For II strategies, it ranged between $\$ 945$ and $\$ 1573$ for strategy IIA, \$563 and \$1869 for strategy IIB, \$662 and $\$ 4085$ for strategy IIC and $\$ 1169$ and $\$ 7897$ for strategy IID. For III strategies, it ranged between $\$ 923$ and $\$ 3116$ for strategy IIIA, $\$ 1005$ and $\$ 2223$ for strategy IIIB, $\$ 883$ and $\$ 4727$ for strategy IIIC and $\$ 1467$ and $\$ 6813$ for strategy IIID (Additional file 3, table 6).
There was considerable overlap between ICER values obtained for each strategy in the 7 years with influenza activity (Fig. 5 and Additional file 3, table 6). Depending on the strategy, $0-3 \%$ of outputs were cost saving, and only $15-39 \%$ of outputs were equal to or less than the upper limit of the WTP threshold of $\$ 872$ (51\% of annual GDP per capita). Using the average INMB values, vaccination was not cost-effective in 2011-2012 at the tested WTP thresholds (Additional file 2, section 6). When comparing age groups, I strategies (vaccinating children 6-23 months of age) had the highest mean INMB values at the lowest WTP values in 5 of 7 years; however in 2015-2016, III strategies (vaccinating 6-14 year olds) had the highest mean INMB at the lowest WTP value (Additional file 2, section 6 and
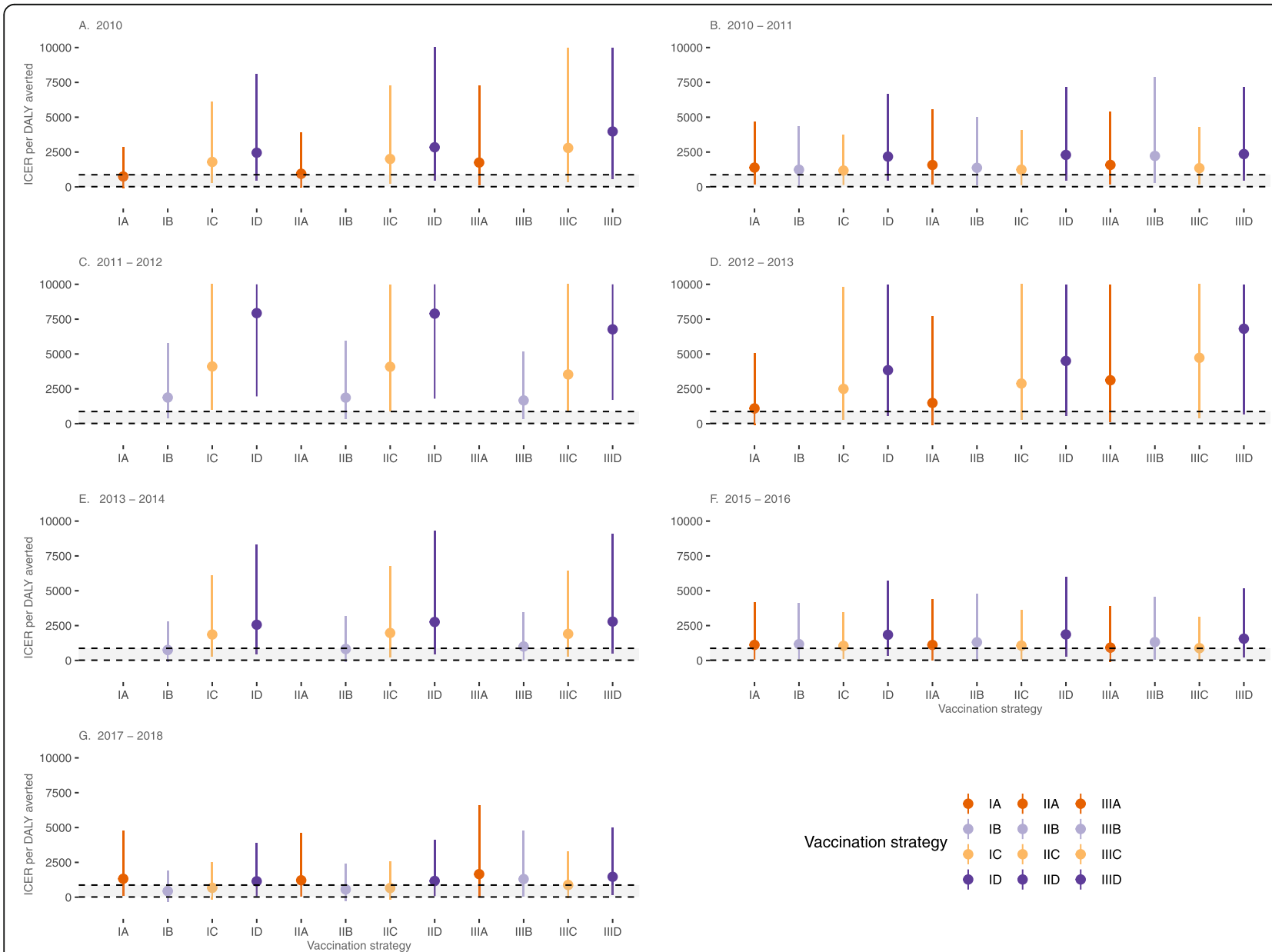

Fig. 5 ICER per DALY averted and 95\% Cl. Results for 2014-15 and 2016-17 are not shown as there were no periods of high influenza activity detected in these years and calculation of ICER values per DALY averted would produce an infinite value as no DALYs would be averted. Similarly, ICER values are not shown for A and B strategies where vaccine administration was mistimed to influenza activity as vaccination was considered ineffective that year. Note the $y$-axes are cut off at 10,000 while actual values may exceed this value. Section shaded grey between the horizontal dotted lines represents outputs that fall within a willingness-to-pay threshold of $1-51 \%$ of the GDP per capita (i.e. between $\$ 17$ and $\$ 872$ ). Values below zero are cost saving. Strategies are vaccinating children 6-23 months (strategy I), 2-5 years (strategy II) and 6-14 years (strategy III) with either the Southern Hemisphere influenza vaccine (Strategy A) or Northern Hemisphere vaccine (Strategy B) or both (Strategy C: twice yearly 3month vaccination periods, or Strategy D: year-round vaccination) 
Additional file 4). In regard to timing of vaccination, A strategies (April-June) and B strategies (October-December) had the highest mean INMB at the lowest WTP values in an equal number of years. $C$ strategies (vaccinating in two 3-month campaigns) were the most costeffective strategies at the upper WTP limit (\$872) in 2010-2011, 2015-2016 and 2017-2018; however, D strategies were never cost-effective at Kenya's range of WTP values (Additional file 2, section 6). On average, across the 7 years of influenza activity, no vaccination strategy was cost-effective at $\$ 17$ (lower limit of WTP range), and $\$ 445$ (median value of WTP range). At $\$ 872$ (upper limit of WTP range), strategy IB had the highest mean INMB; however, it had low probability (3\%) of being the most optimal strategy (Fig. 6, Table 6).

The most favourable vaccination strategy each year was the same regardless of whether total societal costs or only direct medical costs were considered
(Additional file 5); however, the WTP value at which vaccination became cost-effective was higher with direct medical costs (Additional file 2, section 6). Based on the average INMB values across the 7 years of influenza activity, no vaccination strategy was cost-effective at the upper limit of the WTP threshold when only direct medical costs were considered.

\section{Sensitivity analysis}

Removing time discounting led to a $49-50 \%$ reduction in mean ICER per DALY averted across all strategies, and addition of social weighting led to a slight decrease (5-6\%) in mean ICER value. At a vaccine purchase price of $\$ 1.50$ USD, the mean ICER decreased by $44-62 \%$. At a vaccine purchase price of $\$ 10.0$ USD, the mean ICER value increased by $144-178 \%$, and at $\$ 6.0$ USD, the mean ICER value increased by $38-43 \%$, while at a vaccine purchase price of $\$ 4.50$ USD the mean ICER value

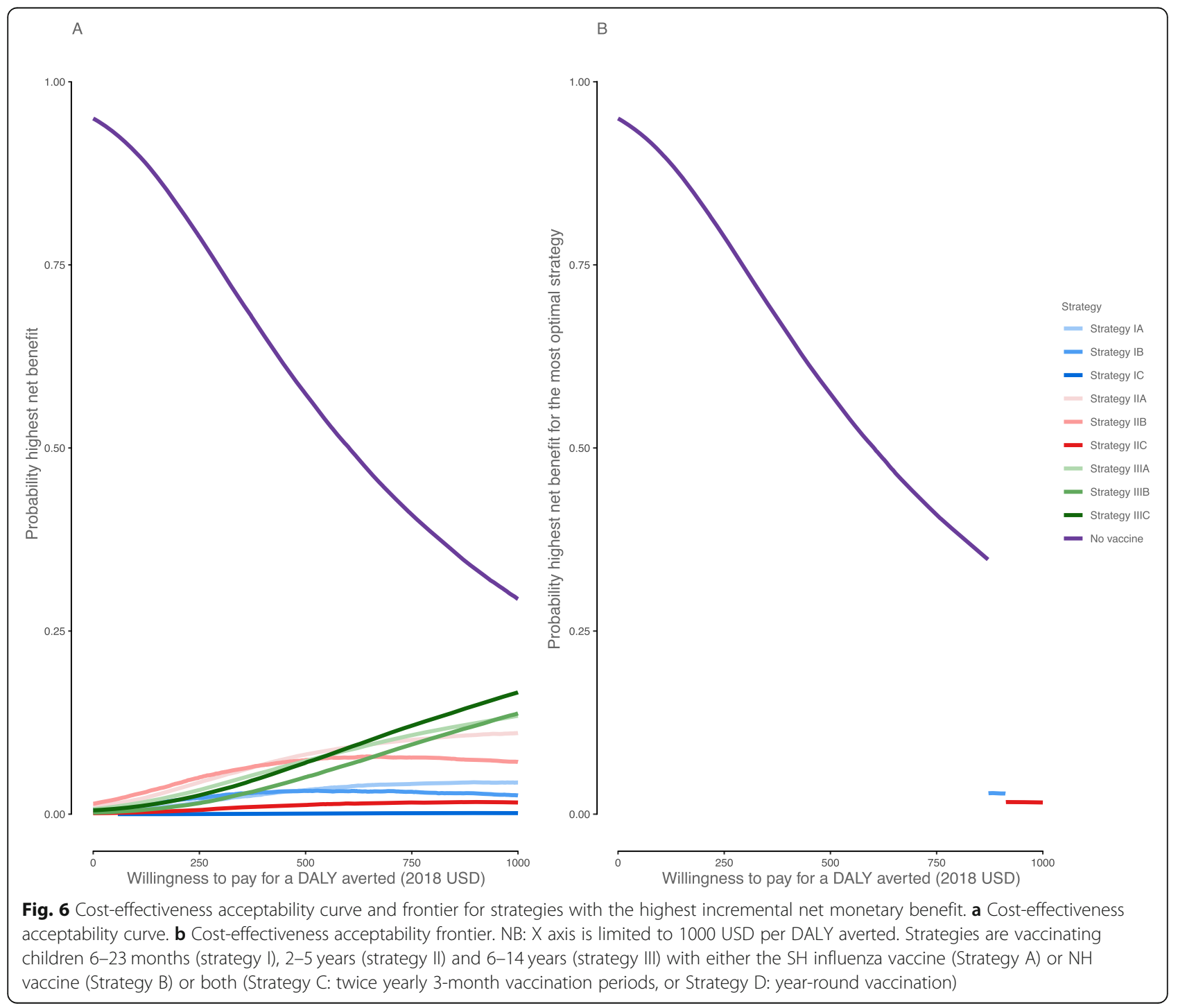


Table 6 Incremental net monetary benefit values and probabilities for each vaccination strategy at a willingness-to-pay threshold of $\$ 872$ per DALY averted

\begin{tabular}{|c|c|c|c|c|c|}
\hline \multirow[t]{2}{*}{ Strategy } & \multirow{2}{*}{$\begin{array}{l}\text { Mean } \\
\text { INMB } \\
\text { value in } \\
\text { '000s }\end{array}$} & \multicolumn{2}{|c|}{ INMB 95\% credible interval in '000 s } & \multirow{2}{*}{$\begin{array}{l}\text { Probability } \\
\text { of highest } \\
\text { INMB } \\
\text { benefit }\end{array}$} & \multirow[t]{2}{*}{ Rank } \\
\hline & & Lower quantile & Upper quantile & & \\
\hline Strategy IA & -472 & -6201 & 10,054 & $4 \%$ & 5 \\
\hline Strategy IB & 3 & -5975 & 13,302 & $3 \%$ & 1 \\
\hline Strategy IC & -217 & -6976 & 13,545 & $0 \%$ & 3 \\
\hline Strategy ID & -3424 & $-10,351$ & 9188 & $0 \%$ & 8 \\
\hline Strategy IIA & -1293 & $-14,377$ & 23,996 & $11 \%$ & 7 \\
\hline Strategy IIB & -581 & $-13,854$ & 28,726 & $7 \%$ & 6 \\
\hline Strategy IIC & -387 & $-15,597$ & 31,947 & $2 \%$ & 4 \\
\hline Strategy IID & -7507 & $-22,440$ & 20,834 & $0 \%$ & 11 \\
\hline Strategy IIIA & -7077 & $-36,674$ & 53,262 & $12 \%$ & 10 \\
\hline Strategy IIIB & -7531 & $-35,320$ & 44,647 & $12 \%$ & 12 \\
\hline Strategy IIIC & -3633 & $-39,244$ & 70,255 & $14 \%$ & 9 \\
\hline Strategy IIID & $-20,326$ & $-54,467$ & 42,876 & $0 \%$ & 13 \\
\hline No vaccine & 0 & - & - & $35 \%$ & 2 \\
\hline
\end{tabular}

INMB incremental net monetary benefit. Strategies are vaccinating children 6-23 months (strategy I), 2-5 years (strategy II) and 6-14 years (strategy III) with either the Southern Hemisphere influenza vaccine (Strategy A) or Northern Hemisphere vaccine (Strategy B) or both (Strategy C: twice yearly 3-month vaccination periods, or Strategy D: year-round vaccination)

increased by $31-38 \%$. Maintaining a uniform vaccine coverage across all age groups led to a $1-4 \%$ decrease in mean ICER value for strategies targeting children 2-5 years, and a $7-20 \%$ reduction in mean ICER values for strategies targeting children 6-14 years. Using the INMB approach, no vaccination strategy was cost-effective at a vaccine price of \$4.5 USD and above. For all other sensitivity analysis outputs, vaccinating children 6-23 months of age with the $\mathrm{NH}$ vaccine (strategy IB) remained the most cost-effective strategy.

\section{Discussion}

There were yearly variations in peaks of influenza activity, with at most three periods of increased influenza activity each year. Rates of infection and hospitalisation were highest in the 1-5 year age group, while mortality rates were highest in individuals $\geq 50$ and children $<5$. As a result, children 1-5 years contributed the highest number of DALYs each year. Given the expected vaccine coverage levels, we found that targeting children 6-23 months in an annual 3-month campaign was the most favourable of the vaccination strategies, although the probability of any vaccination strategy being costeffective, even at the upper limit of the WTP threshold, was low. Vaccination was most cost-effective when vaccine was well matched to circulating strains and influenza activity occurred after hypothetical vaccination campaigns. Vaccinating children 6-23 months of age was least expensive although the reduction in number of infections was not as substantial as those observed at higher coverage levels attainable by vaccinating more children in older age groups. The provisional KENITAG recommendation to vaccinate children 6-23 months would be the least expensive strategy for the government to adopt and frequently had the highest INMB, although at very low probabilities.

Primary school-going children have the highest contact rates in Kenya [22], and therefore, vaccinating this group could yield considerable benefit in all ages due to indirect protection [36]. We found that the overall reduction when vaccinating children $6-14$ years old was only more favourable than vaccinating children 6-23 months of age (who have a higher burden of severe disease) in 2015-2016 when the vaccine was poorly matched to circulating strains. Vaccinating school-going children may be an important strategy when inadequate protection levels are attained in those most susceptible to severe disease [37]. Nonetheless, we found that when the vaccine is well matched to circulating strains, direct protection of the age group with highest burden of severe disease was most favourable. Studies have previously shown that with lower vaccine efficacy the indirect benefit of vaccination exceeds the direct benefits by larger margins [13] and could explain why we obtained more favourable values when vaccinating children $6-14$ years of age in years when vaccine effectiveness was lower.

We found that year-round vaccination was always the least cost-effective strategy. For this strategy, vaccination after infection was more likely to occur. Therefore, vaccinating in short 3-month campaigns was a more 
favourable strategy than year-round vaccination. These findings highlight the need to vaccinate as much of the target population as possible as soon as the influenza vaccine becomes available in order to enjoy the full benefit of vaccination in Kenya. However, evidence of intraseasonal waning immunity and its implications on vaccination timing may lead to changes in recommendations for vaccination timings in future [38-40].

Vaccinating twice a year was most cost-effective at higher WTP values. This strategy would ensure that a proportion of the population has some protection against the currently circulating influenza strains by using the most up-to-date vaccine formulation. Continuous mutations in nucleic acids coding for influenza antigens lead to semi-annual reviews of the components used for the production of influenza vaccine [41]. Over the past 10 years, the strains in the $\mathrm{NH}$ vaccine differed from the incoming $\mathrm{SH}$ vaccine in 6 years and differed from the contents of the preceding $\mathrm{SH}$ vaccine in 3 years [42]. Despite the possibility of waning protection [4345 ], vaccinating once per year should provide some protection over a 12-month period if there is no need for a change in the composition of the $\mathrm{NH}$ and $\mathrm{SH}$ vaccine. Once-a-year vaccination in short 3-month campaigns should be considered; however, surveillance is needed to monitor whether the vaccine is well matched to circulating strains that circulate in the latter half of the year.

In this study, most of the model outputs were unlikely to be cost-effective given a willingness-to-pay threshold of $1-51 \%$ of the GDP. These findings were contingent on a vaccine price per dose of $\$ 3$, which is lower in price than vaccine available in high-income countries [46]. Very few outputs (1\% of all simulations) at the price of $\$ 3$ were cost saving. Overall, vaccination was unlikely to be cost-effective; however, if we had used previous WHO thresholds for cost-effectiveness of health interventions (i.e. (i) very cost-effective if less than the annual GDP per capita, (ii) cost-effective if 1-3 times the GDP, and (iii) not cost-effective if greater than 3 times the GDP [47]), we would have found that vaccination was most likely very cost-effective or cost-effective regardless of the strategy modelled. However, there is debate over the suitability and affordability of the WHO threshold for cost-effectiveness of interventions in LMICs [47, 48] and as an alternative a threshold of $1-51 \%$ GDP per capita for LMICs has been proposed [34]. This lower threshold is postulated to better reflect the constraints within the "supply side" of healthcare funding and considers the opportunity costs of the choice of interventions [34]. Selecting an appropriate ICER threshold value is critical: if interventions that cost more than the appropriate ICER threshold are implemented, they result in a net reduction in health, as more health benefits could be gained by choosing interventions of a lower ICER value [49].

Influenza vaccination of children 6-23 months age was cost-effective at a WTP value of $\$ 872$ per DALY averted, while vaccines already included in the Kenya expanded programme on immunisation (EPI) have considerably lower ICER values. For example, rotavirus vaccine and Haemophilus influenzae type b vaccine cost approximately $\$ 38$ per DALY averted [50, 51], while the pneumococcal vaccine costs $\$ 59$ per DALY averted [52]. Continuing the pneumococcal vaccination programme beyond 2022-2027 when Kenya transitions to the full Gavi price (\$3.05 per dose) would still result in a cost per DALY averted of $\$ 153$ (95\% prediction intervals of \$70-\$411) [53].

In 2010, half of the vaccines provided or considered for provision in LMICs cost less than $\$ 100$ per DALY averted, $25 \%$ cost between $\$ 100$ and $\$ 500$ per DALY averted and $9 \%$ cost between $\$ 500$ and $\$ 1000$ per DALY averted (2010 dollar values) [54]. A decrease in vaccine price and improved influenza vaccine effectiveness, duration of protection, and if possible, long-term immunity would increase influenza vaccine cost-effectiveness and likely adoption in LMICs [55].

Although the range of ICER values per DALY averted were similar among the strategies, the modelled vaccination strategies substantially differed in vaccine purchase costs. Over the past 3 years (2016-2019), the government of Kenya allocated approximately $\$ 7$ million per financial year to the immunisation programme, while Gavi contributed \$26 million per year [56]. We estimated that at a vaccine price of $\$ 3$ per dose, the government would spend \$4.3-\$10.5 million in vaccine purchase costs for the least expensive strategy, and \$25.3-\$54.4 million for the most expensive strategy, which represents a significant proportion of the immunisation budget. Cost differences between strategies could therefore influence selection of vaccination strategy.

Our findings need to be interpreted in light of several limitations. In 2014-2015 and 2016-2017, influenza activity did not meet our decision rule for periods of activity. These periods were characterised by nationwide healthcare worker strikes in public hospitals and disruptions in influenza surveillance funding (2014-2015), both of which plausibly led to a decrease in the number of influenza-positive SARI patients detected. Therefore, our model could have underestimated the burden of influenza and the impact and cost-effectiveness of seasonal influenza vaccination. Indeed, we were not able to fit all the observed periods of influenza activity, which could also underestimate the impact of vaccination over those periods. More complete and robust surveillance data could improve estimates and give further confidence in the findings presented here. 
We limited our burden calculation to periods of high influenza activity. However, the overall rates of hospitalisation across all ages are comparable to past estimates of national disease burden conducted in Kenya covering similar years $[1,57]$. Using a simpler methodology that took into account influenza activity throughout the year, we previously estimated the mean annual rates of influenza-associated hospitalised SARI to be 21 (95\% confidence limit 19-23) per 100,000 population over the period January 2012-December 2014 [1]. For a similar period in our study, September 2011-August 2014, we estimated the mean annual influenza hospitalisation rates to be 24 per 100,000 . These similar results may be explained by the fact that the identified periods of high influenza activity frequently lasted 6 or more months, and likely captured most of the annual influenza activity. Although we focussed on peaks in activity, we obtained comparable rates of illness to studies that considered year-round activity. However, our rates of hospitalised influenza during the early years of this study were slightly lower than previous estimates from August 2010 to July 2011, when published rates of influenzaassociated hospitalised SARI were 70 (95\% confidence limits 50-90) per 100,000 persons [57]. Our estimated rate for the period September 2010-August 2011 was 39 (95\% credible interval 17-69) per 100,000 persons. This disparity may be explained by the fact that we excluded circulation of $\mathrm{A}(\mathrm{H} 1 \mathrm{~N} 1)$ pdm09 from January 2010 to December 2011 during our analysis. We excluded the first 2 years of circulation of the pandemic strain because these epidemics were not a typical influenza season-there was no single peak and numerous small epidemics occurred. This exclusion could have led to underestimation of vaccine cost-effectiveness if vaccines were matched to the pandemic strain during this time. Additionally, if competitive viral interaction were occurring, the circulation of $\mathrm{A}(\mathrm{H} 1 \mathrm{~N} 1) \mathrm{pdm} 09$ could have suppressed $\mathrm{A}(\mathrm{H} 3 \mathrm{~N} 2)$ or $\mathrm{B}$ epidemics, leading to underestimation of vaccine impact.

In this analysis, we assumed that vaccination with $\mathrm{SH}$ or $\mathrm{NH}$ vaccine did not protect against transmission starting in the alternate hemisphere's vaccination period. This assumption was informed by the potential for waning immunity suggested by declining vaccine antibody titres $[58,59]$ and/or possible mismatch of vaccine composition to circulating subtypes [42]. If there were lasting protection [60], there would be a higher impact of the vaccine in later seasons and an increase in costeffectiveness. On the other hand, for periods of influenza activity that fell within a particular vaccination period, we also assumed protection was maintained at a constant level for the duration of influenza activity, regardless of whether the epidemic ran into the next vaccination period, i.e. even when periods of influenza activity lasted more than 6 months. This could lead to overestimation of the impact of vaccination.

We adopted a societal perspective for costs. However, we did not have local data on over-the-counter medication costs, lost wages and childcare costs for nonmedically attended symptomatic influenza cases, and these costs were not incorporated in the analysis. The lack of local data may have led to underestimation of costs as well as the benefits of vaccination. We assumed vaccine completely protects a proportion of those vaccinated, i.e. "all-or-nothing" protection. However, where the influenza vaccine does not prevent infection, it may still reduce the severity and duration of illness [61] which could have underestimated the benefit of vaccination. Finally, we did not include non-respiratory influenza illness in our analysis. Although they are important manifestations of severe influenza, they contribute only $7 \%$ of the total costs of illness and may not have made significant differences to the ICER values [62].

\section{Conclusion}

Influenza vaccination of children 6-23 months of age once per year was the most favourable vaccination strategy; however, it is unlikely to be a cost-effective intervention using a WTP threshold of $1-51 \%$ of annual GDP per capita. Targeting children in older age groups led to the largest reduction in the number of cases but was not necessarily the most cost-effective strategy at our WTP threshold. Further reductions in cost per dose and improvements in vaccine effectiveness and longterm immunity would make the influenza vaccine more attractive for inclusion in the EPI.

\section{Supplementary information}

Supplementary information accompanies this paper at https://doi.org/10. 1186/s12916-020-01687-7.

\footnotetext{
Additional file 1. Influenza surveillance data 2010-2018.

Additional file 2. Supplementary text.

Additional file 3. Additional tables showing: average number of influenza associated disease states and DALYs with their 95\% credible interval limits, (2010-2018) (table on sheet 1); average annual rate per 100,000 of influenza associated disease states with their $95 \%$ credible interval limits, (2010-2018) (table on sheet 2); average number of influenza associated health care utilisation events with their 95\% credible interval limits, (2010-2018) (table on sheet 3); national cost of influenza associated illness across all ages, (2010-2018) (table on sheet 4); average annual costs and 95\% credible intervals (Cls) per vaccination strategy in millions of USD (table on sheet 5); incremental cost-effectiveness ratio for influenza vaccination using total societal costs (table on sheet 6).

Additional file 4. Yearly cost-effectiveness acceptability curves and frontiers for strategies with the highest incremental net monetary benefit considering total societal costs. NB: $X$ axis is limited to 1000 USD per DALY averted. Strategies are vaccinating children 6-23 months (strategy I), 2-5 years (strategy II) and 6-14 years (strategy III) with either the SH influenza vaccine (Strategy A) or NH vaccine (Strategy B) or both (Strategy C: twice yearly 3-month vaccination periods, or Strategy D: year-round vaccination)
} 
Additional file 5. Yearly cost-effectiveness acceptability curves and frontiers for strategies with the highest incremental net monetary benefit considering direct medical costs only. NB: $X$ axis is limited to 1000 USD per DALY averted. Strategies are vaccinating children 6-23 months (strategy I), 2-5 years (strategy II) and 6-14 years (strategy III) with either the $\mathrm{SH}$ influenza vaccine (Strategy A) or NH vaccine (Strategy B) or both (Strategy C: twice yearly 3-month vaccination periods, or Strategy D: yearround vaccination).

\section{Abbreviations}

A(H1N1)pdm09: Influenza A H1N1pdm09; A(H3N2): Influenza A H3N2; CDC: Centers for Disease Control and Prevention; Cl: Credible intervals; DALY: Disability-adjusted life year; EPI: Expanded programme on immunisation; ICER: Incremental cost-effectiveness ratio; INMB: Incremental net monetary benefit; KENITAG: Kenya National Immunisation Technical Advisory Group; LMICs: Low- and middle-income countries; LRT: Lower respiratory tract; MCMC: Markov chain Monte Carlo; NH: Northern Hemisphere; NP: Nasopharyngeal; OP: Oropharyngeal; rRT-PCR: Real-time reverse transcription-polymerase chain reaction; SARI: Severe acute respiratory illness; SEIR: Susceptible-Exposed-Infectious-Recovered; SH: Southern Hemisphere; URT: Upper respiratory tract; VE: Vaccine effectiveness; WHO: World Health Organization; WTP: Willingness-to-pay

\section{Acknowledgements}

The authors acknowledge the assistance of the Ministry of Health, Kenya Medical Research Institute and Centers for Disease Control and Prevention for sharing surveillance data on severe acute respiratory illness and influenzaassociated respiratory illness, the KEMRI-Wellcome Trust Research Programme, Kilifi, Kenya, for sharing raw data on age-related contact patterns in Kilifi, Kenya and the Kenya Education Network (KENET) and London School of Hygiene \& Tropical Medicine (LSHTM) for providing the computing resources used during the analysis. We also gratefully acknowledge Mark Jit, Nichola Naylor and Jonathan Yoder for helpful comments and technical discussion, and Sam Clifford, Peter Macharia, Charles Opondo, Mutono Nyamai, Fanuel Otieno and Evans Omondi for technical assistance.

The statements made and views expressed are solely the responsibility of the authors and do not necessarily represent the official position of the U.S. Centers for Disease Control and Prevention (CDC) or any of the funding or acknowledged institutions or persons.

\section{Authors' contributions}

All authors participated in the conceptualisation of the study. JD conducted the analysis and was supervised by RME. JD adapted a previously published method for which R code had been developed by EVL and MB. SSC and GE provided the influenza surveillance data. Original draft of the manuscript was prepared by JD and RME. JD and RME worked on visualisation/data presentation. All authors interpreted the results and edited the manuscript. All authors read and approved the final manuscript.

\section{Funding}

JD received funding from (a) the Consortium for Advanced Research Training in Africa (CARTA) (http://cartafrica.org). CARTA is jointly led by the African Population and Health Research Center and the University of the Witwatersrand and funded by the Carnegie Corporation of New York (Grant no:: B 8606.R02), Sida (Grant no.: 54100113 ), the DELTAS Africa Initiative (Grant no.: 107768/Z/15/Z) and Deutscher Akademischer Austauschdienst (DAAD). The DELTAS Africa Initiative is an independent funding scheme of the African Academy of Sciences (AAS)'s Alliance for Accelerating Excellence in Science in Africa (AESA) and supported by the New Partnership for Africa's Development Planning and Coordinating Agency (NEPAD Agency) with funding from the Wellcome Trust (UK) and the UK government and, (b) the Tropical Diseases Modelling (TDMOD) network (http://www.tdmod.net). EB is funded by a Wellcome Trust core grant awarded to the KEMRI-Wellcome Trust Research Programme (Grant no:: 092654) (https://wellcome.ac.uk/). EvL acknowledges funding from the National Institute for Health Research through the Health Protection Research Unit in Respiratory Infections at Imperial College London (https://www.imperial.ac.uk/medicine/nihr-hprurespiratory-infections) in partnership with Public Health England. RME acknowledges funding from (a) an HDR UK Innovation Fellowship (Grant no.: MR/S003975/1) (https://www.hdruk.ac.uk/) and (b) the National
Institute for Health Research through the Health Protection Research Unit in Immunisation (http://immunisation.hpru.nihr.ac.uk/) at the London School of Hygiene \& Tropical Medicine in partnership with Public Health England. No funding bodies had any role in study design, data collection and analysis, decision to publish or preparation of the manuscript.

\section{Availability of data and materials}

All data generated or analysed during this study are included in this published article and its supplementary information files.

\section{Ethics approval and consent to participate}

Permission to undertake secondary data analysis of de-identified SARI surveillance data collected from patients admitted at county referral hospitals, was obtained from the Kenyatta National Hospital - University of Nairobi Ethics Review Committee (P18/01/2017).

\section{Consent for publication}

Not applicable.

\section{Competing interests}

The authors declare that they have no competing interests.

\section{Author details}

${ }^{1}$ KAVI-Institute of Clinical Research, College of Health Sciences, University of Nairobi, Nairobi, Kenya. ${ }^{2}$ Washington State University Global Health Programs Kenya Office, Nairobi, Kenya. ${ }^{3}$ Influenza Program, Centers for Disease Control and Prevention, Nairobi, Kenya. ${ }^{4}$ Health Economics Research Unit, KEMRI Wellcome Trust Research Programme, Nairobi, Kenya. ${ }^{5}$ Center for Tropical Medicine, Nuffield Department of Medicine, University of Oxford, Oxford, UK. ${ }^{6}$ Division of Global Health Protection, Center for Global Health, Centers for Disease Control and Prevention, Nairobi, Kenya. ${ }^{7}$ Division of Global Health Protection, Center for Global Health, Centers for Disease Control and Prevention, Atlanta, GA, USA. ${ }^{8}$ Public Health England, London, UK. 'London School of Hygiene \& Tropical Medicine, London, UK. ${ }^{10}$ Imperial College London, London, UK. ${ }^{11}$ Influenza Division, National Center for Immunization and Respiratory Diseases, US Centers for Disease Control and Prevention, Atlanta, GA, USA.

Received: 5 December 2019 Accepted: 29 June 2020

Published online: 20 August 2020

\section{References}

1. Dawa JA, Chaves SS, Nyawanda B, Njuguna HN, Makokha C, Otieno NA, et al. National burden of hospitalized and non-hospitalized influenzaassociated severe acute respiratory illness in Kenya, 2012-2014. Influenza Other Respir Viruses. 2018;12(1):30-7.

2. Emukule GO, Paget J, van der Velden K, Mott JA. Influenza-Associated Disease Burden in Kenya: A Systematic Review of Literature. PLoS One. 2015; 10(9):1-14.

3. Office of Director of Medical Services Ministry of Health. Communication to stakeholders: Progress update on plans to introduce influenza vaccine into routine immunization in Kenya. Nairobi: Ministry of Health, Kenya; 2016.

4. Dawa J, Chaves SS, Ba Nguz A, Kalani R, Anyango E, Mutie D, et al. Developing a seasonal influenza vaccine recommendation in Kenya: process and challenges faced by the National Immunization Technical Advisory Group (NITAG). Vaccine. 2019;37(3):464-72.

5. Ott JJ, Klein Breteler J, Tam JS, Hutubessy RC, Jit M, de Boer MR. Influenza vaccines in low and middle income countries: a systematic review of economic evaluations. Hum Vaccines Immunotherapeutics. 2013;9(7):1500-11.

6. Salleras L, Navas E, Torner N, Prat AA, Garrido P, Soldevila N, et al. Economic benefits of inactivated influenza vaccines in the prevention of seasonal influenza in children. Hum Vaccines Immunotherapeutics. 2013;9(3):707-11.

7. World Health Organisation. Which vaccine formulation to use - Northern or Southern Hemisphere? 2017. Available from: https://www.who.int/influenza/ vaccines/tropics/vaccination_formulation/en/[updated 12 September 2017; cited 2019 June 22].

8. World Health Organisation. Vaccination timing 2017. Available from: https:// www.who.int/influenza/vaccines/tropics/vaccination_timing/en/. [updated 12 September 2017; cited 2019 June 22]. 
9. Katz MA, Muthoka P, Emukule GO, Kalani R, Njuguna H, Waiboci LW, et al. Results from the first six years of national sentinel surveillance for influenza in Kenya, July 2007-June 2013. PLoS One. 2014;9(6):e98615.

10. Waiboci LW, Mott JA, Kikwai G, Arunga G, Xu X, Mayieka L, et al. Which influenza vaccine formulation should be used in Kenya? A comparison of influenza isolates from Kenya to vaccine strains, 2007-2013. Vaccine. 2016; 34(23):2593-601.

11. Yue M, Dickens BL, Yoong JS-Y, I-Cheng Chen M, Teerawattananon Y, Cook AR. Cost-effectiveness analysis for influenza vaccination coverage and timing in tropical and subtropical climate settings: a modeling study. Value in Health. 2019:22(12):1345-54.

12. Mertz D, Fadel SA, Lam PP, Tran D, Srigley JA, Asner SA, et al. Herd effect from influenza vaccination in non-healthcare settings: a systematic review of randomised controlled trials and observational studies. Euro surveillance : bulletin Europeen sur les maladies transmissibles = European communicable disease bulletin. 2016;21(42):1-9.

13. Eichner M, Schwehm M, Eichner L, Gerlier L. Direct and indirect effects of influenza vaccination. BMC Infect Dis. 2017;17(1):308.

14. Pitman R, Fisman D, Zaric GS, Postma M, Kretzschmar M, Edmunds J, et al. Dynamic transmission modeling: a report of the ISPOR-SMDM Modeling Good Research Practices Task Force-5. Value Health. 2012;15(6):828-34.

15. Baguelin M, Jit M, Miller E, Edmunds WJ. Health and economic impact of the seasonal influenza vaccination programme in England. Vaccine. 2012; 30(23):3459-62.

16. Baguelin M, Flasche S, Camacho A, Demiris N, Miller E, Edmunds WJ. Assessing optimal target populations for influenza vaccination programmes: an evidence synthesis and modelling study. PLoS Med. 2013;10.

17. Ministy of Health. Kenya Master Health Facility List: Government of Kenya; 2020. Available from: http://kmhfl.health.go.ke/\#/gis. [cited 2020 3 March].

18. Chaves SS, Aragon D, Bennett N, Cooper T, D'Mello T, Farley M, et al. Patients hospitalized with laboratory-confirmed influenza during the 20102011 influenza season: exploring disease severity by virus type and subtype. J Infect Dis. 2013;208(8):1305-14.

19. Noor AM, Zurovac D, Hay SI, Ochola SA, Snow RW. Defining equity in physical access to clinical services using geographical information systems as part of malaria planning and monitoring in Kenya. Trop Med Int Health. 2003;8(10):917-26.

20. Emukule GO, Mott JA, Spreeuwenberg P, Viboud C, Commanday A, Muthoka P, et al. Influenza activity in Kenya, 2007-2013: timing, association with climatic factors, and implications for vaccination campaigns. Influenza Other Respir Viruses. 2016;10(5):375-85.

21. Baguelin M, Camacho A, Flasche S, Edmunds WJ. Extending the elderly- and risk-group programme of vaccination against seasonal influenza in England and Wales: a cost-effectiveness study. BMC Med. 2015;13(1):1-13.

22. Kiti MC, Kinyanjui TM, Koech DC, Munywoki PK, Medley GF, Nokes DJ. Quantifying age-related rates of social contact using diaries in a rural coastal population of Kenya. PLoS One. 2014;9(8):e104786.

23. van Leeuwen $E$, Klepac $P$, Thorrington D, Pebody R, Baguelin M fluEvidenceSynthesis: An R package for evidence synthesis based analysis of epidemiological outbreaks. PLOS Comput Biol. 2017;13(11):e1005838.

24. R Core Team. R: a language and environment for statistical computing Vienna: R Foundation for Statistical Computing; 2016.

25. Katz MA, Lebo E, Emukule GO, Otieno N, Caselton DL, Bigogo G, et al. Uptake and effectiveness of a trivalent inactivated influenza vaccine in children in urban and rural Kenya, 2010-2012. Pediatr Infect Dis J 2015:35(3): 322-9.

26. World Health Organisation. Correlates of vaccine-induced protection: methods and implications. Geneva: World Health Organisation; 2013.

27. Carrat F, Vergu E, Ferguson NM, Lemaitre M, Cauchemez S, Leach S. Time lines of infection and disease in human influenza: a review of volunteer challenge studies. Am J Epidemiol. 2008;167:775-85.

28. Institute for Health Metrics and Evaluation (IHME). Global Burden of Disease Study 2016 (GBD 2016) Disability Weights 2019 [cited 2019 June 9]. Available from: http://ghdx.healthdata.org/record/ihme-data/gbd-2016disability-weights.

29. de Boer PT, Kelso JK, Halder N, Nguyen T-P-L, Moyes J, Cohen C, et al. The cost-effectiveness of trivalent and quadrivalent influenza vaccination in communities in South Africa, Vietnam and Australia. Vaccine. 2018;36(7): 997-1007.
30. Emukule GO, Ndegwa LK, Washington ML, Paget JW, Duque J, Chaves SS, et al. The cost of influenza-associated hospitalizations and outpatient visits in Kenya. BMC Public Health. 2019;19(3):471.

31. Mvundura M, Lorenson K, Chweya A, Kigadye R, Bartholomew K, Makame $M$, et al. Estimating the costs of the vaccine supply chain and service delivery for selected districts in Kenya and Tanzania. Vaccine. 2015;33(23): 2697-703.

32. World Health Organisation. Monitoring vaccine wastage at country level. Guidelines for programme managers. Geneva: World Health Organisation; 2005

33. Devleesschauwer B, Havelaar AH, Maertens de Noordhout C, Haagsma JA, Praet N, Dorny P, et al. Calculating disability-adjusted life years to quantify burden of disease. Int J Public Health. 2014;59(3):565-9.

34. Woods B, Revill P, Sculpher M, Claxton K. Country-level cost-effectiveness thresholds: initial estimates and the need for further research. Value Health. 2016;19(8):929-35.

35. World Health Organisation. WHO guide for standardization of economic evaluations of immunization programmes. 2nd ed. Geneva: World Health Organisation; 2019.

36. Piedra PA, Gaglani MJ, Kozinetz CA, Herschler G, Riggs M, Griffith M, et al. Herd immunity in adults against influenza-related illnesses with use of the trivalent-live attenuated influenza vaccine (CAIV-T) in children. Vaccine. 2005;23(13):1540-8.

37. Glezen WP. Herd protection against influenza. J Clin Virol. 2006;37(4):237-43.

38. Costantino V, Trent M, MacIntyre CR. Modelling of optimal timing for influenza vaccination as a function of intraseasonal waning of immunity and vaccine coverage. Vaccine. 2019;37(44):6768-75.

39. Ferdinands JM, Alyanak E, Reed C, Fry AM. Waning of influenza vaccine protection: exploring the trade-offs of changes in vaccination timing among older adults. Clin Infect Dis. 2019;70(8):1550-9.

40. Newall AT, Chen C, Wood JG, Stockwell MS. Within-season influenza vaccine waning suggests potential net benefits to delayed vaccination in older adults in the United States. Vaccine. 2018;36(39):5910-5.

41. World Health Organisation. Vaccines against influenza WHO position paper, November 2012. 2012 47(87 ):461-76.

42. World Health Organisation. WHO recommendations on the composition of influenza virus vaccines 2019. Available from: https:/www.who.int/influenza/ vaccines/virus/recommendations/en/. [updated 2019; cited 2019 July 5].

43. Ferdinands JM, Fry AM, Reynolds S, Petrie J, Flannery B, Jackson ML, et al. Intraseason waning of influenza vaccine protection: evidence from the US influenza vaccine effectiveness network, 2011-12 through 2014-15. Clin Infect Dis. 2017;64(5):544-50.

44. Puig-Barbera J, Mira-Iglesias A, Tortajada-Girbes M, Lopez-Labrador FX, Librero-Lopez J, Diez-Domingo J, et al. Waning protection of influenza vaccination during four influenza seasons, 2011/2012 to 2014/2015. Vaccine. 2017;35(43):5799-807.

45. Ray GT, Lewis N, Klein NP, Daley MF, Wang SV, Kulldorff M, et al. Intraseason waning of influenza vaccine effectiveness. Clin Infect Dis. 2019;68(10):1623-30.

46. Centers for Disease Control and Prevention (CDC). CDC Vaccine Price List 2019. Available from: https://www.cdc.gov/vaccines/programs/vfc/ awardees/vaccine-management/price-list/index.html. [updated 1 September 2019; cited 2019 November 11].

47. Marseille E, Larson B, Kazi DS, Kahn JG, Rosen S. Thresholds for the costeffectiveness of interventions: alternative approaches. Bull World Health Organ. 2015;93(2):118-24.

48. Leech AA, Kim DD, Cohen JT, Neumann PJ. Use and misuse of costeffectiveness analysis thresholds in low- and middle-income countries: trends in cost-per-DALY studies. Value Health. 2018;21(7):759-61.

49. Revill P, Ochalek J, Lomas J, Nakamura R, Woods B, Rollinger A, et al. Costeffectiveness thresholds: guiding health care spending for population health improvement [version 1; not peer reviewed]. F1000Research. 2017; 6(489):1-24.

50. Sigei C, Odaga J, Mvundura M, Madrid Y, Clark AD. Cost-effectiveness of rotavirus vaccination in Kenya and Uganda. Vaccine. 2015;33:A109-A18.

51. Akumu AO, English M, Scott JA, Griffiths UK. Economic evaluation of delivering Haemophilus influenzae type $b$ vaccine in routine immunization services in Kenya. Bull World Health Organ. 2007:85(7):511-8.

52. Ayieko P, Griffiths UK, Ndiritu M, Moisi J, Mugoya IK, Kamau T, et al. Assessment of health benefits and cost-effectiveness of 10-valent and 13valent pneumococcal conjugate vaccination in Kenyan children. PLoS One. 2013;8(6):e67324. 
53. Ojal J, Griffiths U, Hammitt LL, Adetifa I, Akech D, Tabu C, et al. Sustaining pneumococcal vaccination after transitioning from Gavi support: a modelling and cost-effectiveness study in Kenya. Lancet Glob Health. 2019;7(5):e644-e54.

54. Ozawa S, Mirelman A, Stack ML, Walker DG, Levine OS. Cost-effectiveness and economic benefits of vaccines in low- and middle-income countries: a systematic review. Vaccine. 2012;31(1):96-108.

55. MacLennan CA. Vaccines for low-income countries. Semin Immunol. 2013; 25(2):114-23.

56. Government of Kenya. National and County Health Budget Analysis 2018/ 2019. In: Ministry of Health. Nairobi: Government of Kenya; 2019.

57. Fuller JA, Summers A, Katz MA, Lindblade KA, Njuguna H, Arvelo W, et al. Estimation of the national disease burden of influenza-associated severe acute respiratory illness in Kenya and Guatemala: a novel methodology. PLoS One. 2013;8(2):e56882.

58. Cox N. Editorial: influenza seasonality: timing and formulation of vaccines. Bull World Health Organisation. 2014;92(5):309-84.

59. Rambhia KJ, Rambhia MT. Early bird gets the flu: what should be done about waning intraseasonal immunity against seasonal influenza? Clin Infect Dis. 2018;68(7):1235-40.

60. Zhou F, Trieu M-C, Davies R, Cox RJ. Improving influenza vaccines: challenges to effective implementation. Curr Opin Immunol. 2018;53:88-95.

61. Arriola C, Garg S, Anderson EJ, Ryan PA, George A, Zansky SM, et al. Influenza vaccination modifies disease severity among community-dwelling adults hospitalized with influenza. Clin Infect Dis. 2017:65(8):1289-97.

62. Tempia S, Moyes J, Cohen AL, Walaza S, Edoka I, McMorrow ML, et al. Health and economic burden of influenza-associated illness in South Africa, 2013-2015. Influenza and other respiratory viruses. 2019;13(5):484-95.

\section{Publisher's Note}

Springer Nature remains neutral with regard to jurisdictional claims in published maps and institutional affiliations.

Ready to submit your research? Choose BMC and benefit from:

- fast, convenient online submission

- thorough peer review by experienced researchers in your field

- rapid publication on acceptance

- support for research data, including large and complex data types

- gold Open Access which fosters wider collaboration and increased citations

- maximum visibility for your research: over $100 \mathrm{M}$ website views per year

At $\mathrm{BMC}$, research is always in progress.

Learn more biomedcentral.com/submissions 